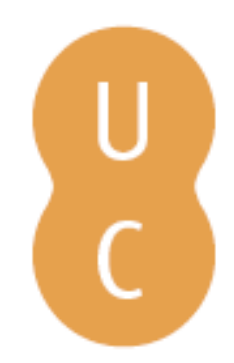

\title{
pombalina
}

Os Sistemas Geotérmicos Estimulados (EGS/HDR): um desafio para o século XXI

Autor(es): $\quad$ Neves, Luís; Pereira, Alcides; Dias, José Matos

Publicado por: Imprensa da Universidade de Coimbra; Laboratório de Radioactividade Natural da Universidade de Coimbra

URL

persistente: URI:http://hdl.handle.net/10316.2/36309

DOI: $\quad$ DOI:http://dx.doi.org/10.14195/978-989-26-1009-2_20

Accessed : $\quad$ 26-Apr-2023 11:30:32

A navegação consulta e descarregamento dos títulos inseridos nas Bibliotecas Digitais UC Digitalis, UC Pombalina e UC Impactum, pressupõem a aceitação plena e sem reservas dos Termos e Condições de Uso destas Bibliotecas Digitais, disponíveis em https://digitalis.uc.pt/pt-pt/termos.

Conforme exposto nos referidos Termos e Condições de Uso, o descarregamento de títulos de acesso restrito requer uma licença válida de autorização devendo o utilizador aceder ao(s) documento(s) a partir de um endereço de IP da instituição detentora da supramencionada licença.

Ao utilizador é apenas permitido o descarregamento para uso pessoal, pelo que o emprego do(s) título(s) descarregado(s) para outro fim, designadamente comercial, carece de autorização do respetivo autor ou editor da obra.

Na medida em que todas as obras da UC Digitalis se encontram protegidas pelo Código do Direito de Autor e Direitos Conexos e demais legislação aplicável, toda a cópia, parcial ou total, deste documento, nos casos em que é legalmente admitida, deverá conter ou fazer-se acompanhar por este aviso. 


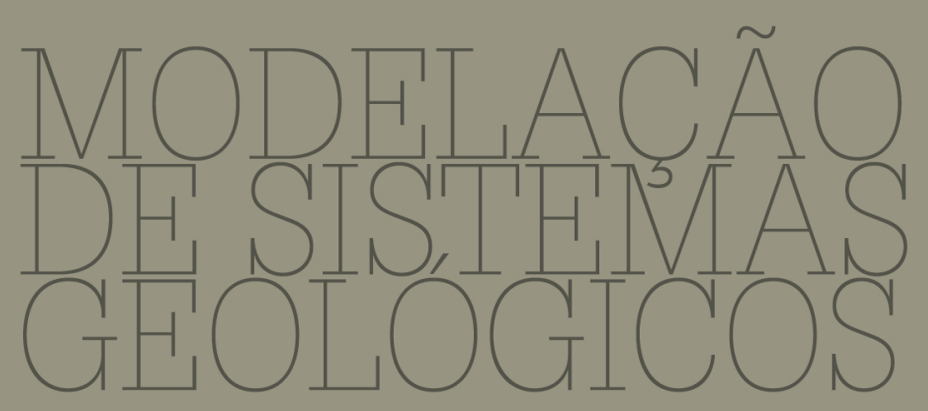

Homenagem ao Professor Doutor Manuel Maria Godinho

L.J.P.F. Neves, A.J.S.C. Pereira,

C.S.R. Gomes, L.C.G. Pereira,

A.O. TAVARES

IMPRENSA DA UNIVERSIDADE DE COIMBRA

CoImBra University Press 


\title{
MODELAÇÃO \\ DE SISTEMAS \\ GEOLÓGICOS
}

Homenagem ao Professor Manuel Maria Godinho

\section{Os Sistemas Geotérmicos Estimulados (EGS/HDR) - um desafio para o século XXI}

\author{
Luís Neves ${ }^{1}$; Alcides Pereira ${ }^{1}$; José Matos Dias ${ }^{1}$ \\ ${ }^{1}$ IMAR, Departamento de Ciências da Terra, Universidade de Coimbra, Portugal
}

Palavras-chave: Geotermia, EGS, HDR, Portugal

\section{Resumo}

A Geotermia constitui uma fonte renovável de energia, não carecendo da intermitência de outras alternativas aos combustíveis fósseis, como a energia solar, eólica ou hídrica. É utilizada desde há um século para produção de electricidade em contextos geológicos favoráveis, inseridos em regiões de vulcanismo activo e muito elevado fluxo térmico, como é o caso dos Açores. Apresenta igualmente campos de aplicação em franco desenvolvimento no domínio da climatização, individual ou colectiva. Desenvolvimentos tecnológicos recentes tornaram viável, através dos Sistemas Geotérmicos Estimulados (EGS/HDR), a recuperação do calor interno da Terra em regiões não vulcânicas, através da constituição de reservatórios geotérmicos a $4-5 \mathrm{~km}$ de profundidade, sendo requisito para o efeito a ocorrência de temperaturas mínimas de $200^{\circ} \mathrm{C}$ às profundidades referidas. Não obstante o território nacional apresentar indicadores favoráveis à implementação deste tipo de tecnologia, as grandes lacunas ainda existentes no conhecimento geológico do subsolo tornam mais oneroso e arriscado para as empresas o investimento nesta tecnologia emergente comparativamente a outros países estrangeiros.

Keywords: Geothermal energy, EGS, HDR, Portugal

\begin{abstract}
The internal heat of the Earth is a renewable source of energy not affected by the intermittency of other alternatives to fossil fuels like solar, eolic and hydroelectric power. It has been used to produce electricity in the last one hundred years, typically in areas of very high heat flow with active volcanism, like the Azores. Heat pumps for domestic climatization and direct district heating are also fast growing areas of application of geothermal energy. Recent technological developments allowed to extend electricity production to areas without active volcanism, where minimum temperatures of $200^{\circ} \mathrm{C}$ can be achieved at a depth of 4-5 km, through Engineered Geothermal Systems (formerly HDR - Hot Dry Rock). Portugal presents some favourable geological indications to this type of technology, however important gaps in the knowledge of the deep structure of the crust presents and increased economic risk for companies interested to invest.
\end{abstract}




\section{Introdução}

O desenvolvimento mundial sustentado da produção de energia eléctrica a partir de diversas fontes renováveis é uma resultante do aumento vertiginoso do custo dos combustíveis fósseis (temporariamente interrompido pela crise económica mundial iniciada em 2008), de uma forte pressão ambiental decorrente da libertação de gases com efeito de estufa e do previsível esgotamento, a médio prazo, destes recursos geológicos não renováveis. Segundo dados da Agência Internacional de Energia prevê-se que, até 2030, o crescimento da procura de energia eléctrica cresça $120 \%$ no sector residencial, $100 \%$ nos serviços e $85 \%$ na indústria. O consumo mundial total de energia eléctrica será de 1436 MTep em 2010 (17\% de toda a energia consumida) e de 2263 MTep em 2030 (20\% de toda a energia consumida). A previsível electricificação do parque automóvel mundial, ainda em fase embrionária, poderá contribuir para um crescimento mais acelerado do consumo mundial de energia eléctrica.

Actualmente, a produção de energia eléctrica está geralmente associada às grandes centrais de combustíveis fósseis (carvão, petróleo e gás), centrais hídricas e nucleares. No que se refere à utilização mundial de recursos renováveis a liderança vai para os recursos hídricos $(90 \%)$. No entanto a Agência Internacional de Energia prevê que, em 2030, se verifique uma descida nesta última componente para $70 \%$. Esta diminuição resultará do aumento percentual da obtenção de energia eléctrica a partir de outras fontes renováveis (a biomassa de $7 \%$ para $10 \%$, a eólica de $2 \%$ para $15 \%$, a geotermia de $2 \%$ para $3 \%$, a fotovoltaica de menos de $1 \%$ para $2 \%$ e a energia dos oceanos de inexpressiva para $c a .1 \%$ ).

Visando a redução da dependência dos combustíveis fósseis, a Comissão Europeia delineou um plano estratégico até 2010, e nesse plano perspectivou que as fontes de energia renovável duplicassem o seu contributo de 6 para $12 \%$ do consumo energético total, visando uma redução de $15 \%$ das emissões dos gases com efeito de estufa relativamente a 1990 . Em 2010, a Comissão Europeia adoptou um novo plano estratégico, perspectivando, agora, até 2020, o desenvolvimento de: a) novas tecnologias para redes inteligentes e armazenamento de energia; b) uma investigação na segunda geração de biocombustíveis; c) parcerias para cidades inteligentes, visando a redução de consumos em áreas urbanas. Os objectivos quantificados são os de reduzir as emissões de gases com efeito de estufa em $20 \%$, incrementar a quota das energias renováveis para $20 \%$ e alcançar $20 \%$ de melhorias de eficiência no uso da energia. 


\section{A Geotermia - conceitos gerais}

Geotermia é a designação usada para as ciências e técnicas que estudam e exploram o calor da Terra. As tecnologias geotérmicas que pretendem explorar o calor da terra têm um largo campo de desenvolvimento, atendendo a que $99 \%$ da massa do planeta se encontra a uma temperatura superior a $1000^{\circ} \mathrm{C}$ e apenas uma ínfima proporção se situa abaixo de $100^{\circ} \mathrm{C}$.

São diversas as aplicações da geotermia, que, por convenção, se dividem entre as de alta e de baixa entalpia. A geotermia de alta entalpia implica a existência de fluidos a temperatura elevada, geralmente superior a $150^{\circ} \mathrm{C}$, e propicia a produção de energia eléctrica; não obstante, o desenvolvimento tecnológico das centrais binárias já permite a produção de energia eléctrica a temperaturas inferiores a $150^{\circ} \mathrm{C}$, ainda que com eficiência reduzida. A geotermia de baixa entalpia é orientada para a climatização, podendo distinguir-se como variante os aproveitamentos directos do calor e a utilização do subsolo como meio de permuta térmica (bombas de calor geotérmicas).

Nos últimos anos, o segmento das bombas de calor geotérmicas tem apresentado um notável crescimento, na climatização de edifícios. Neste tipo de aproveitamento tira-se partido da estabilidade térmica do subsolo pois a partir de 1-2 metros de profundidade (e até algumas dezenas de metros) a temperatura permanece relativamente estável durante todo o ano, não sofrendo as fortes amplitudes térmicas sazonais que afectam a atmosfera. Este facto permite realizar, com vantagem, no Verão, a extracção de calor do interior das habitações e sua dissipação no subsolo, e no Inverno a captura de calor a partir do subsolo e a sua introdução nas habitações. A eficiência do processo é muito superior relativamente aos sistemas convencionais de ar condicionado, dada a estabilidade térmica do meio permutador que permite uma significativa redução da factura energética para o mesmo nível de conforto. Esta técnica implica a colocação de tubagens no subsolo, dispostas na horizontal, caso exista espaço suficiente em torno do edifício ou, quando tal espaço seja inexistente, na vertical, através de vários furos com profundidade de algumas dezenas de metros. No interior das tubagens circula um fluido que concretiza a permuta térmica com o subsolo. O comprimento total das tubagens de permutação deve ser dimensionado de acordo com o rendimento obtido, rendimento que depende das características geológicas do terreno e da potência pretendida. Os rendimentos médios rondam os $50 \mathrm{~W}$ por metro, podendo ascender a 70-80 W em condições geológicas favoráveis. A distribuição do calor/frio deverá ser realizada através de pisos/paredes radiantes, o que implica a colocação do sistema de raíz na fase de construção dos edifícios, ou por ocasião de 
profundas remodelações. Nestas condições, o custo do kWh no ciclo de vida é inferior ao apresentado pela generalidade das soluções existentes baseadas em combustíveis fósseis (gás, diesel) ou em soluções puramente eléctricas. A utilização mundial das bombas de calor geotérmicas sextuplicou na última década, prosseguindo em acelerado crescimento. Um caso exemplar de aplicação é o terminal E do aeroporto de Zurique, com $2100 \mathrm{MWh}$ anuais de aquecimento assegurados a partir de 300 furos com 30 metros cada. Globalmente, para uma potência instalada de 1,5 GWt na Europa, produzem-se anualmente $2,8 \mathrm{TWh}$.

A geotermia de baixa entalpia é aplicada essencialmente em utilizações directas do calor para aquecimento pela extracção de fluidos quentes existentes em profundidade, em contacto com as rochas (a algumas dezenas de ${ }^{\circ} \mathrm{C}$ ) - o primeiro aproveitamento na escala residencial foi realizado em 1892 em Boise (Idaho, EUA). Na Europa, para uma potência instalada de cerca de $6 \mathrm{GWt}$, obtém-se uma produção anual da ordem de 22 TWht. Tirando partido das condições naturais, a Islândia é o país mais avançado neste tipo de utilizações, sendo a capital, Reikjavik, integralmente aquecida a partir de fontes geotérmicas, bem como diversas outras cidades. A potência instalada a nível mundial é estimada em 28 GW. Em Portugal Continental existem apenas alguns aproveitamentos de baixa entalpia associados a balneoterapia, com maior expressão em S. Pedro do Sul e Chaves (Lourenço \& Cruz, 2005; Gomes, 2007). Pelos custos de instalação envolvidos, trata-se de uma tecnologia tipicamente usada em bairros ou cidades, o que permite a partilha do investimento na infraestrutura. Do ponto de vista económico é altamente rentável, sendo particularmente adequada aos países frios, onde o aquecimento representa a quase totalidade dos requisitos de climatização. $\mathrm{O}$ aproveitamento da geotermia de baixa entalpia depende, da existência de condições geológicas que favoreçam a presença de fluidos quentes próximos da superfície topográfica, e da capacidade de gestão dos aproveitamentos que deve assegurar que a extração do fluído geotérmico não seja superior à recarga natural, evitando assim a rápida exaustão do recurso.

A geotermia de alta entalpia, visando a produção de energia eléctrica, teve início em Larderello (Itália), em 1911. Requer a existência combinada de três factores geológicos: a) a existência de um gradiente geotérmico invulgarmente elevado; b) a existência de fluidos subterrâneos em contacto com a rocha quente; c) a existência de permeabilidade que permita a percolação dos fluidos e o inerente contacto com um significativo volume de rocha quente. Em geral, os requisitos referidos apenas são encontrados em locais específicos de algumas regiões particulares do globo, 
fundamentalmente na proximidade dos bordos de placas tectónicas onde existe vulcanismo activo. A raridade da conjugação de tais factores e a limitação geográfica da sua ocorrência leva a que, não obstante a elevada competitividade da energia eléctrica produzida, a expressão mundial seja pouco significativa (ca. $10 \mathrm{GW}$ em 2010). Os principais países produtores são os EUA (3,1 GW), as Filipinas (1,9 GW), a Indonésia (1,2 GW), o México $(1,0 \mathrm{GW})$, a Itália $(0,8 \mathrm{GW})$, a Nova Zelândia $(0,6 \mathrm{GW})$ a Islândia $(0,6 \mathrm{GW})$ e o Japão $(0,5 \mathrm{GW})$. Em Portugal, as condições geológicas adequadas a este tipo de aproveitamento são atingidas nos Açores - onde na ilha de S. Miguel são, nesta base, supridas $c a$. 40\% das necessidades de energia elétrica. A potência instalada é de $23 \mathrm{MW}$, existindo planos de expansão para a ilha Terceira.

A produção de energia eléctrica é assegurada por centrais de vapor seco, quando o fluido geotérmico recolhido é constituído por vapor. O vapor é introduzido directamente numa turbina que, subsequentemente, acciona um gerador. Quando o fluido geotérmico se encontra no estado líquido (como resultado da elevada pressão no reservatório), são utilizadas centrais do tipo flash. Neste caso, o fluido é recolhido sob pressão e injectado num compartimento hermético, onde se realiza a sua despressurização, o que induz a ebulição da água e a libertação súbita (flash) de vapor que, por sua vez, acciona uma turbina. A água residual pode ser reinjectada no reservatório geotérmico por forma a prolongar o seu tempo de vida. A reinjecção de fluidos tem sido realizada com sucesso, sendo paradigmático o caso do campo geotérmico The Geysers, nos EUA, que tem recebido a água residual processada nos sistemas de tratamento da cidade de Santa Rosa. Um terceiro tipo de centrais de produção de energia eléctrica são as centrais binárias, em franco desenvolvimento nos anos mais recentes. Neste caso, o fluido geotérmico não é directamente utilizado na central, sendo utilizados permutadores para transferir o seu calor para um fluido secundário com baixo ponto de ebulição (isobutano, isopentano ou similares) que vaporiza e acciona a turbina. As centrais binárias permitem produzir energia eléctrica a partir de fluidos a temperaturas muito inferiores às necessárias em centrais de vapor seco ou do tipo flash, existindo centrais comerciais a operar a $120^{\circ} \mathrm{C}$. Alguns desenvolvimentos recentes sugerem que, a curto prazo, será possível operar com fluidos a temperaturas da ordem dos $70-80^{\circ} \mathrm{C}$. As centrais do tipo binário têm ainda a vantagem de não emitir gases para a atmosfera, uma vez que o fluido geotérmico opera em circuito fechado. Em geral, a profundidade de operação dos sistemas geotérmicos convencionais para produção de energia eléctrica não excede os $2 \mathrm{~km}$. 


\section{O Conceito EGS/HDR}

O conceito de "Hot Dry Rock" surgiu no final dos anos 70 como resposta às primeiras crises petrolíferas, tendo em vista alargar significativamente as áreas geográficas do globo susceptíveis de poderem produzir energia eléctrica a partir de fontes geotérmicas. Após alguns anos de investigação nos anos 80 e 90, onde foram desenvolvidos diversos projectos experimentais (Fenton Hill, Coso, Desert Peak, Glass Mountain e The Geysers/Clear Lake, nos EUA; Rosemanowes, na Inglaterra; Soultz-sousForêt e Le Mayet de Montagne, em França; Hijiori e Ogachi, no Japão; Falkenberg, Horstberg, e Bad Urach, na Alemanha; Basel e Geneve, na Suíça; e Fjallbacka, na Suécia (MIT (2006)). Este conceito viria a ser esquecido em consequência da era de petróleo barato que então se iniciou. Em Portugal, foram realizados alguns estudos académicos de que é exemplo o de Godinho et al. (2001). Inevitavelmente, este conceito iria ressurgir no início do presente século, uma vez mais como em reacção às flutuações do preço do petróleo, desta vez sob a designação de EGS - "Engineered ou "Enhanced Geothermal Systems". O conceito é relativamente simples, consistindo no aproveitamento do calor produzido no interior da Terra por rochas localizadas a profundidades de 4 a $6 \mathrm{~km}$ abaixo da superfície, em zonas de gradiente geotérmico apenas, marginalmente, superior ao normal. Atendendo à escassa probabilidade de existência de fluidos em quantidades significativas a tais profundidades e à reduzida permeabilidade expectável, a criação de um reservatório geotérmico passa pela estimulação hidráulica das rochas, induzindo a sua fissuração e subsequente injecção de fluidos a partir da superfície. Desta forma, dos três requisitos naturais determinantes para a criação de um reservatório geotérmico, dois são em alternativa assegurados por técnicas de engenharia, sendo apenas necessário que exista rocha quente com a temperatura adequada $\left(>150{ }^{\circ} \mathrm{C}\right)$, o que justifica a designação de EGS. O reservatório geotérmico deverá ter um volume significativo, da ordem de $1 \mathrm{~km}^{3}$ ou mais, por forma a que o processo de extracção do calor possa persistir durante 20 a 30 anos sem decréscimo exagerado da temperatura da rocha. Este é o tempo suficiente para rentabilizar economicamente o projecto.

Os notáveis progressos da indústria petrolífera alcançados nos últimos anos relativamente à perfuração profunda e ao desenvolvimento de técnicas de estimulação hidráulica, contribuiram de forma notória para o ressurgimento do ideal EGS que teve a prova de conceito, no ano de 2008, no projecto experimental da UE localizado em Soultz-sous-Forêt (França), com o início da produção de energia eléctrica numa central piloto de 1,5 MW (actualmente em fase de expansão para $6 \mathrm{MW}$ ). O reservatório 
geotérmico situa-se a $5 \mathrm{~km}$ de profundidade, a temperatura de $c a .200^{\circ} \mathrm{C}$ (Figura 1), desenvolvendo-se em rocha granítica. $\mathrm{O}$ reservatório é alimentado por um furo de injecção (GPK3), com débito de $100 \mathrm{~kg} / \mathrm{s}$, sendo a água recolhida após percolar a rocha através de dois furos de recuperação (GPK2 e GPK4), que distam 600 metros cada do furo do injeção. A água é conduzida para uma central binária à superfície, onde chega a $c a \cdot 180^{\circ} \mathrm{C}$, e após permutação do calor novamente reinjectada no reservatório.

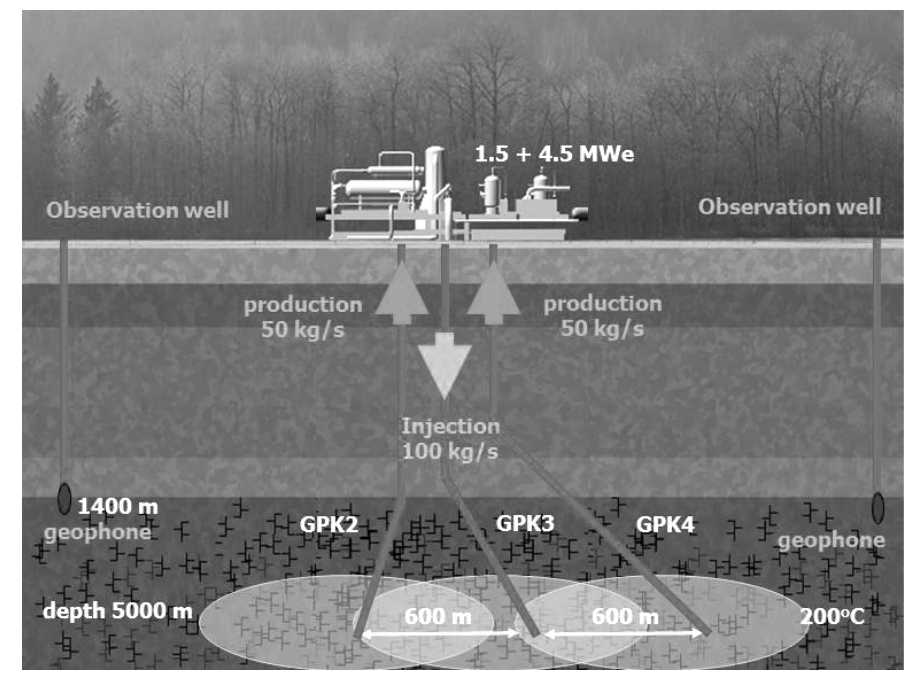

Figura 1. Diagrama ilustrativo do projecto experimental de Soultz-sous-Forêt (reproduzido de www.soultz.net).

O conceito EGS tem mobilizado, recentemente, um grande número de projectos em todo o mundo, boa parte dos quais com capitais privados. Só na Austrália, até Março de 2007, foram solicitadas mais de 100 licenças de áreas de prospecção e pesquisa para HDR, com área total de mais de 62000 $\mathrm{Km}^{2}$. Nesses projectos estão envolvidas 16 empresas, a maioria cotadas em bolsa. O projecto Habanero, da empresa Geodynamics, localizado na região de Cooper Basin, no ano de 2008 concluiu, com sucesso, a fase de estimulação hidráulica e connecção entre os furos, preparando-se no final de 2009 para o início da produção experimental de energia; contudo, o colapso de um dos furos levou ao refazer dos trabalhos, esperando-se que ocorra a reactivação do projecto ainda em 2010. O objectivo da Geodynamics é o de ter uma potência de $500 \mathrm{MW}$ instalada neste local até 2020, tirando partido de uma situação geológica muito favorável. Existem dezenas de projectos 
em diferentes etapas de desenvolvimento e em diferentes zonas desde a Austrália, Suíça, Estados Unidos, ou Alemanha e Espanha, entre outras.

$\mathrm{O}$ calor utilizado pela geotermia HDR/EGS resulta de dois componentes aditivos. Um deles corresponde à dissipação térmica, por condução, do calor armazenado no planeta (fluxo térmico basal). O outro decorre do calor gerado nas próprias rochas através do decaimento dos isótopos radiogénicos de potássio, tório e urânio, bem como dos gerados nas suas cadeias de decaimento. É de salientar que o decaimento radioactivo nas rochas do planeta Terra gera o equivalente a $30 \mathrm{TW}$ de potência energética, o que ultrapassa largamente o consumo mundial. A energia geotérmica pode, por conseguinte, ser considerada uma energia renovável.

A geotermia convencional é normalmente desenvolvida em regiões com vulcanismo activo, onde o fluxo térmico basal é localmente muito elevado. No que respeita à tecnologia EGS, continua a ser relevante a implementação de projectos em locais onde o gradiente geotérmico seja um pouco superior à média crustal de $25-30^{\circ} \mathrm{C}$, uma vez que cada projecto exige vários furos profundos e os custos de execução crescem de forma não linear com a profundidade. A existência de um gradiente geotérmico local ou regional acrescido pode resultar de diversos factores geológicos como sejam: a existência de actividade magmática relativamente recente em termos geológicos; a presença de volumes significativos de rochas ricas em elementos radiogénicos, e como tal possuindo elevadas produções de calor interno. Os aspectos tectónicos são também relevantes: designadamente, a existência de grabens preenchidos com alguns quilómetros de sedimentos sobrepostos a rochas graníticas constitui um dos cenários geológicos mais favoráveis, uma vez que os sedimentos actuam como um "cobertor" que isola em parte o fluxo térmico proveniente dos granitos os quais se encontram tipicamente enriquecidos em elementos radiogénicos e, como tal, produzem níveis acrescidos de calor. Uma discussão mais detalhada sobre este assunto pode ser encontrada em Genter et al. (2003); Pereira e Neves (2011).

Note-se, para concluir, que um quilómetro cúbico de granito com temperatura de $250^{\circ} \mathrm{C}$ armazena energia correspondente a 40 milhões de barris de petróleo se a extracção for efectuada através de um fluido à temperatura de $150^{\circ} \mathrm{C}$. É de salientar que um quilómetro cúbico de granito (com uma massa de aproximadamente 2500 milhões de toneladas) necessita de menos de 100000 toneladas de circulação de água para extrair o seu calor. Apenas é necessário expor $1 / 25000$ partes da massa do granito à circulação da água para que tal aconteça. 


\section{Vantagens competitivas da geotermia EGS/HDR}

A geotermia é a única fonte conhecida de energia renovável com capacidade para produzir electricidade de forma praticamente contínua. A taxa de disponibilidade verificada nas centrais geotérmicas é superior a $90 \%$, chegando a superar a das centrais baseadas em combustíveis fósseis e é 4 a 5 vezes superior à alcançada por fontes como a eólica e a solar. É, por conseguinte, a única fonte de energia alternativa que pode, potencialmente, substituir os combustíveis fósseis e a energia nuclear na produção da energia de base que tem de ser constantemente assegurada na rede eléctrica. Para além desta característica relevante, ao contrário das outras fontes de energia, convencionais ou alternativas, cuja disponibilidade é limitada por diversos factores intrínsecos, na geotermia o recurso (calor interno da Terra) é ilimitado e o seu aproveitamento apenas se encontra dependente do engenho humano. Na vertente ambiental, a geotermia assegura a produção de energia eléctrica mais limpa, sem emissão de gases com efeito de estufa ou outro tipo de poluentes, não gerando igualmente resíduos perigosos.

Num exaustivo estudo intitulado "The future of Geothermal Energy" elaborado em 2006 pelo Massachusetts Institute of Technology (MIT), por solicitação do Governo dos Estados Unidos da América, é afirmado: "Geothermal energy from EGS represents a large, indigenous resource that can provide base-load electric power and heat at a level that can have a major impact on the United States, while incurring minimal environmental impacts. With a reasonable investment in $R \& D$, EGS could provide 100 GWe or more of cost-competitive generating capacity in the next 50 years. Further, EGS provides a secure source of power for the long term that would help protect America against economic instabilities resulting from fuel price fluctuations or supply disruptions. Most of the key technical requirements to make EGS work economically over a wide area of the country are in effect, with remaining goals easily within reach." As conclusões do relatório, ainda que respeitantes aos EUA, podem ser estendidas à maior parte das regiões do globo.

Do ponto de vista económico, as centrais geotérmicas convencionais apresentam custos de produção por kWh próximos dos obtidos com base em combustíveis fósseis. No que se refere ao EGS/HDR, na presente fase em que a tecnologia se pode ainda considerar imatura, é de prever que os custos sejam significativamente mais elevados, com tendência, contudo, para descerem com o aumento do número de projectos bem sucedidos e a subsequente aprendizagem tecnológica. Adoptar uma nova ideia, mesmo quando apresenta vantagens que parecem óbvias, é uma tarefa difícil e 
requer normalmente um período longo desde a prova do conceito até à sua aceitação generalizada.

Por este facto, diversos países estão a apoiar activamente este tipo de energia, através da atribuição de preços mais favoráveis de compra da energia produzida, geralmente situados entre os atribuídos à energia eólica e à energia solar. A transformação de energia geotérmica em electricidade é uma indústria de capital intensivo e muito dependente de alta tecnologia. $\mathrm{O}$ investimento de capital pode ser dividido em três fases distintas: a) selecção de áreas com potencialidades; b) sondagens para produção; c) construção de estações de produção de electricidade. De acordo com um estudo de viabilidade económica efectuado pelo MIT, integrado no trabalho já referenciado (MIT, 2006), os custos de produção previstos situam-se entre 6 e 11 cêntimos USD por kWh (Figura 2) quando a tecnologia atingir a sua maturidade. O cenário base foi elaborado para uma instalação de 3 furos de produção para um de injeção separados por distâncias de 500 metros, para um débito de geofluído de $80 \mathrm{Kg} / \mathrm{s}$ por furo de produção, uma temperatura no fundo do furo de $400^{\circ} \mathrm{C}$ e uma taxa de diminuição da temperatura de $3 \%$ ao ano. Os parâmetros financeiros utilizados no modelo para o cenário base foram um rácio de dívida relativamente ao capital de 60/40 e uma taxa de juro de $8 \%$. A rendibilidade do investimento é de $17 \%$.

Os custos de perfuração constituem um dos factores com maior peso no custo final da energia produzida, pelo que os desenvolvimentos tecnológicos neste domínio poderão potenciar grandemente o uso da geotermia. É também expectável que prossiga a evolução técnica das centrais binárias, permitindo produzir energia eléctrica a partir de fluidos com temperaturas mais reduzidas e melhorando a eficiência da extracção.

$\mathrm{O}$ número de países produtores de energia geotérmica bem como a capacidade instalada aumentaram significativamente desde o início da década, passando de $21 \mathrm{com} \mathrm{8,7} \mathrm{GW,} \mathrm{actualmente,} \mathrm{para} 46$ com 13,5 GW. A International Geothermal Association estima que em 2050, com o advento da tecnologia EGS, a produção mundial de energia eléctrica de fontes geotérmicas possa vir a ascender a $150 \mathrm{GW}$.

Um aspecto a acautelar no desenvolvimento de projectos EGS prendese com o risco da indução de sismicidade na fase de estimulação hidráulica e de exploração, o que reforça a necessidade da realização de estudos geológicos rigorosos. 


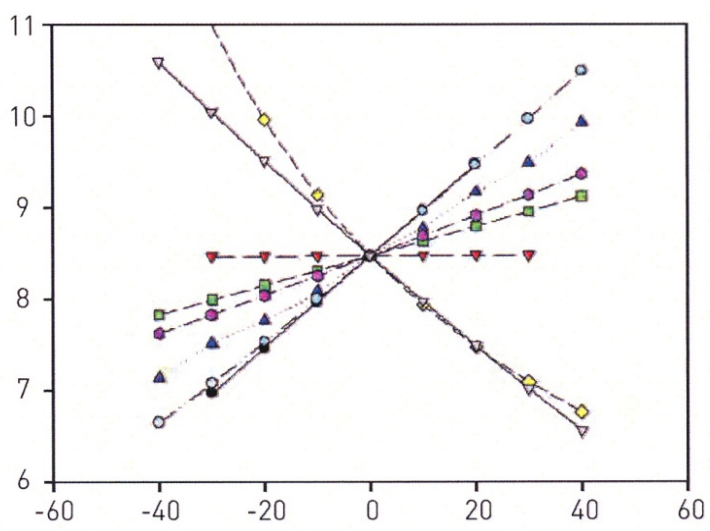

Figura 2. Efeito da variação de diversos factores face ao cenário base (em abcissas, \%) sobre o custo final da energia eléctrica produzida (em ordenadas, cêntimos de USD). Os factores considerados são, na metade esquerda do gráfico e de cima para baixo, os seguintes: débito do fluido geotérmico; rácio dívida/capital (\%); custo da estimulação hidráulica; custo da central de produção de energia; taxa de juro; taxa de redução da temperatura do reservatório; rendibilidade do capital (\%); custos da perfuração e de instalação dos sistemas.

A nível europeu, alguns dos contextos mais favoráveis à implementação deste tipo de projectos caracterizam-se pela sua inserção em áreas tectonicamente activas, o que potencia este risco. O projecto de Basileia, na Suíça, exemplifica o risco referido, dado que a indução de dois sismos de pequena intensidade (3.4 e 3.1 na escala de Richter) em Dezembro de 2006 e Janeiro de 2007, sentidos pelas populações e causando estragos em alguns edifícios, levou à suspensão do projecto (Baisch et al., 2010).

\section{O caso do território nacional}

Em 2008 várias empresas apresentaram projectos de prospecção e pesquisa visando a produção de energia eléctrica a partir de fontes geotérmicas no território continental português: foi o caso da Martifer, da Kernow Resources \& Development e da Geovita. O contexto geológico dos diversos projectos sugere que apenas o da empresa Geovita se enquadra no conceito EGS/HDR, correspondendo, os restantes, a uma tipologia mais próxima da geotermia convencional. O projecto da Geovita, com suporte científico do Departamento de Ciências da Terra da Universidade de Coimbra, resultou de estudos de reavaliação do potencial geotérmico do Centro e Norte de Portugal realizados em 2007 (ver Pereira \& Neves, 2011), e do subsequente pedido dirigido à Direcção Geral de Energia e Geologia em Abril de 2008 
de atribuição de uma área de prospecção e pesquisa na região das Beiras. Esta área, com $c a$. $530 \mathrm{~km}^{2}$, foi outorgada pela DGEG à Geovita em Dezembro de 2008, tendo em Janeiro de 2009 sido concedido um ponto de ligação à rede eléctrica nacional com potência de $3 \mathrm{MW}$. Em Agosto de 2009 foi atribuído um preço garantido de venda da energia eléctrica de 0,27 $€$ por $\mathrm{kWh}$, que é dos mais elevados da Europa. O projecto previa o investimento de $1 \mathrm{M} €$ no prazo de $3+2$ anos, na fase de prospecção e pesquisa; contudo, as dificuldades decorrentes da crise económica iniciada em 2008 levaram ao adiamento dos trabalhos, procurando a Geovita encontrar parcerias que permitam viabilizar a sua concretização. Estimativas realizadas com base em informação disponível e seguindo o mesmo procedimento do MIT (2006) para o território dos EUA, sugerem que, na área concessionada para efeitos de prospecção e pesquisa, entre os 3 e os 10 $\mathrm{km}$ de profundidade, possa existir 2295 EJ enquanto recurso energético, o que compara com o consumo anual de 0,18 EJ do país em 2005. A recuperação de $2 \%$ do recurso disponível corresponderia a mais de 250 vezes tal consumo.

\section{Considerações finais}

Portugal vem concretizando um significativo investimento em energias renováveis, com forte aposta na energia eólica, hídrica e, em menor grau, na energia solar - as razões para este facto são do conhecimento geral, incluindo motivações de carácter ambiental e de redução da dependência externa.

As energias renováveis referidas apresentam, infelizmente, limitações intrínsecas que as condenam a constituírem uma solução orientada para a minimização do consumo de combustíveis fósseis, e não para a sua completa substituição. Tal situação resulta da intermitência da produção energética baseada no sol, no vento e na chuva, o que obriga à existência de soluções de recurso inevitavelmente baseadas em fontes não renováveis.

A geotermia, pelo carácter inesgotável do calor da Terra e permanente disponibilidade do recurso, apresenta um enorme potencial de desenvolvimento futuro, no domínio da climatização de edifícios e no da produção de energia eléctrica. De entre o conjunto das fontes renováveis, é a única energia alternativa que permite assegurar o nível de produção base necessário às redes eléctricas, dada a sua taxa de disponibilidade superior a $90 \%$, constituindo, nesta perspectiva, o único substituto conhecido aos combustíveis fósseis e à energia nuclear. As limitações actuais na utilização da energia geotérmica, resultantes da heterogeneidade da distribuição 
geográfica das fontes de calor ao nível do planeta, são susceptíveis de ser ultrapassadas com o advento da maturidade tecnológica dos inovadores sistemas geotérmicos estimulados (EGS/HDR). Contudo, na fase actual, os problemas de financiamento decorrentes da crise económica mundial iniciada em 2008 constituem um entrave significativo ao desenvolvimento de projectos EGS, em particular na Europa, por serem projectos de capital intensivo, o qual não se encontra disponível ou tem um custo muito elevado para investimentos de risco. Tal não impede que prossigam algumas evoluções tecnológicas, sendo notórios os progressos alcançados nos últimos anos designadamente no domínio da melhoria do rendimento das centrais binárias. Algumas tecnologias promissoras, de que é exemplo a utilização de lasers na perfuração, têm potencial para produzir súbitos e relevantes acréscimos de competitividade económica aos projectos EGS.

No que respeita ao território continental português, o desenvolvimento de projectos EGS enfrenta ainda, para além das dificuldades referidas, algumas outras de carácter nacional resultantes da quantidade e, por vezes, da qualidade do conhecimento da base de recursos geotérmicos. Encontram-se bem estabelecidos os procedimentos a seguir na fase de prospecção e pesquisa de recursos geotérmicos, que são do domínio público e devidamente regulados no âmbito dos Decretos-Lei 87/90 e 90/90 de 16 de Março, competindo à Direcção Geral de Energia e Geologia a qualificação de um fluido ou de uma formação geológica como recurso geotérmico. Contudo, as empresas interessadas em investir neste domínio enfrentam uma desvantagem competitiva face a outros países europeus, resultante da falta de conhecimento geológico de superfície e, em particular, da estruturação crustal profunda, sendo igualmente muito escassa a informação existente sobre fluxos térmicos. Por conseguinte, nos estádios iniciais de desenvolvimento de uma nova tecnologia será preferível em termos de custo-eficácia investir em $\mathrm{R} \& \mathrm{D}$ em fase preliminar à dos projetos de produção.

Agradecimentos: Os autores dedicam o presente trabalho ao Professor Manuel Maria Godinho, o qual foi pioneiro na avaliação do potencial das rochas granitóides portuguesas para a geotermia HDR.

\section{Bibliografia}

Baisch, S., Martin, C., Serianex Group (2010) - Seismic risk analysis of the Basel geothermal (EGS) project. Proceedings of the 32th General Assembly of the European Seismological Commission, p. 63. 
Genter, A., Guillou-Frottier, L., Feybesse, J.-L., Nicol, N., Dezayes, C., Shwartz, S. (2003) Typology of potential Hot Fractured Rock resources in Europe. Geothermics; 32, 701-710.

Godinho, M.M., Pereira, A.J.S.C., Neves, L.J.P.F. (1991) - Potencial térmico das rochas graníticas num segmento do Maciço Hespérico (Portugal Central). Memórias e Notícias, Publ. Mus. Lab. Mineral. Geol. Univ. Coimbra; 112, 469-483.

Gomes, L.M.F (2007) - Aproveitamento em cascata em São Pedro do Sul. Boletim de Minas; 42 (1), 5-17.

Lourenço, C., Cruz, J. (2005) - Aproveitamentos geotérmicos em Portugal Continental. XV Encontro Nacional do Colégio de Engenharia Geológica e de Minas da Ordem dos Engenheiros, 1-9.

MIT (2006) - The future of geothermal energy.

http://www1.eere.energy.gov/geothermal/future_geothermal.html.

Pereira, A.J.S.C., Neves, L.J.P.F. (2011) - Potencial EGS/HDR da região Centro e Norte de Portugal. "Modelação de Sistemas Geológicos", livro de Homenagem ao Professor Manuel Maria Godinho, neste volume.

Rogers, E. M. (2003) - Diffusion of innovations. New York, Free Press. 